\title{
Geovisualization based upon KML
}

\section{Marianna Zichar}

\section{N F O}

Received 11 Nov. 2011

Accepted 06 Feb. 2012

Available on-line 15 Jun. 2012

Responsible Editor: K. Rajkai

Keywords:

GIS, geovisualization, creating and sharing $\mathrm{kml}$, application fields.

\begin{abstract}
$\underline{\text { A B S T R A C T }}$
The extension $\mathrm{kml}$ refers to a human readable file format that is based on a markup language deriving from XML and became rather popular mainly due to Google Earth. This type of files uses not only the classical geometric data, but coordinates of longitude and latitude (in case of 3D system also coordinate of altitude) to visualize the different geographically referenced objects, phenomena and processes. Nowadays more than 10 millions of $\mathrm{kml}$ files are available via the internet covering several topics from agriculture, health care, environment protection, geology, etc. Agriculture is a typical field, where geovisualization based upon $\mathrm{kml}$ files can be a very effective way of publishing data and this influenced me to review the characterictics of $\mathrm{kml}$, to highlight some of its application, and to share some personal experiences.
\end{abstract}

\section{Introduction}

The Keyhole Markup Language (KML) is an XML notation for describing features whose geographic location plays an important role in their lifecycle. Virtual globes and two-dimensional online maps are the most frequent used applications to display the content of a $\mathrm{kml}$ file, but nowadays other representing methods are also available and several disciplines (life sciences, economics, linguistics, agriculture, geology etc.) do use it for different purposes. The usage of $\mathrm{kml}$ files does not concentrate only to the desktop application of Google Earth any more, but there are several other GIS programs as well as other softwares (such as SketchUp, Blender, online mapping applications) that are capable to process or to import kml files. In agriculture quite a number of application fields can be found that implies to review this aspect in detail.

The other concept from the title, geovisualization, refers to a specific way of representing georelated objects where the visualization is based upon data referring to the location of the objects. Even in agriculture, it is not hard to find objects (e.g. fields, forests), events (e.g. irrigation, spraying crops), processes (e.g. floods, forest fire) or phenomena (e.g. hail) whose representation can be more attractive and informative if we use the data about their geographical locations as well. Glancing at a map with georeferenced data can promote its understanding rather than browsing the rows in a table.

\section{The main characteristics of KML}

The beginning of the success story of KML is related to the appearance of Google Earth. It is its whole name, Keyhole Markup Language, that remembers us even nowadays to the name of the company, originally started to create KML, although Google bought it up in 2004, and finally its popularity was based upon Google's activity. It was a significant event when the KML Version 2.2 with the name of OpenGIS KML 2.2 Encoding Standard, has been adopted as an OGC (Open Geospatial Consortium) implementation standard for presenting geographic information visually (Wilson, 2008). The OGC has developed a broad Standards Baseline and having KML fit within that family has encouraged users and developers to work with it more frequently.

A file with extension $\mathrm{kml}$ is, basically, a simple text file that can be opened with a simple text editor to reach its content. The language belongs to the family of markup languages and organizes its elements into a hierarchical tree structures (Figure 1). A valid $\mathrm{kml}$ file has to meet the following requirements (Wernecke, 2009):

- Case is significant.

- The order of KML elements is significant. 
- Child elements can belong only to the allowed parent element.

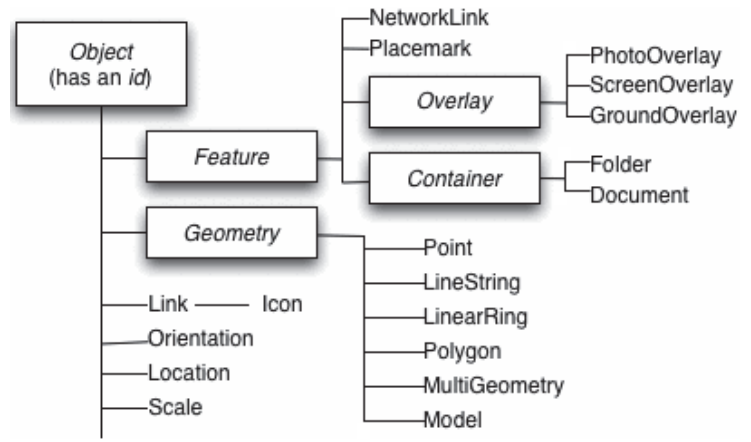

Figure 1. A snippet of the hierarchical tree of KML elements

Although these rules seem to be simple, keeping them can be a demanding work until we are used to them. Elements can have derived elements that inherit elements from their parents and can have their own ones as well. The rectangles in Figure 1. represent abstract elements that cannot be instantiate in a $\mathrm{kml}$ file, they have to be substituted for any other element derived from them. The most-widely used element to denote a point on the surface of the Earth is the Placemark with geometry of Point and a Placemark is the only place to put Geometry elements in KML. A geographic location is defined by longitude, latitude, and (optionally) altitude, but their order differs from that in other systems (Figure 2.). If a Placemark contains a Point element, then its coordinates also determine the location of the label and the icon. A connected, not closed set of line segments can be defined by element LineString while Polygon refers to an object with area and is defined by an outer boundary and if it is needed by additional inner boundaries. Boundaries have LinearRing geometry and their first and last coordinates have to coincide to denote the property of being closed.
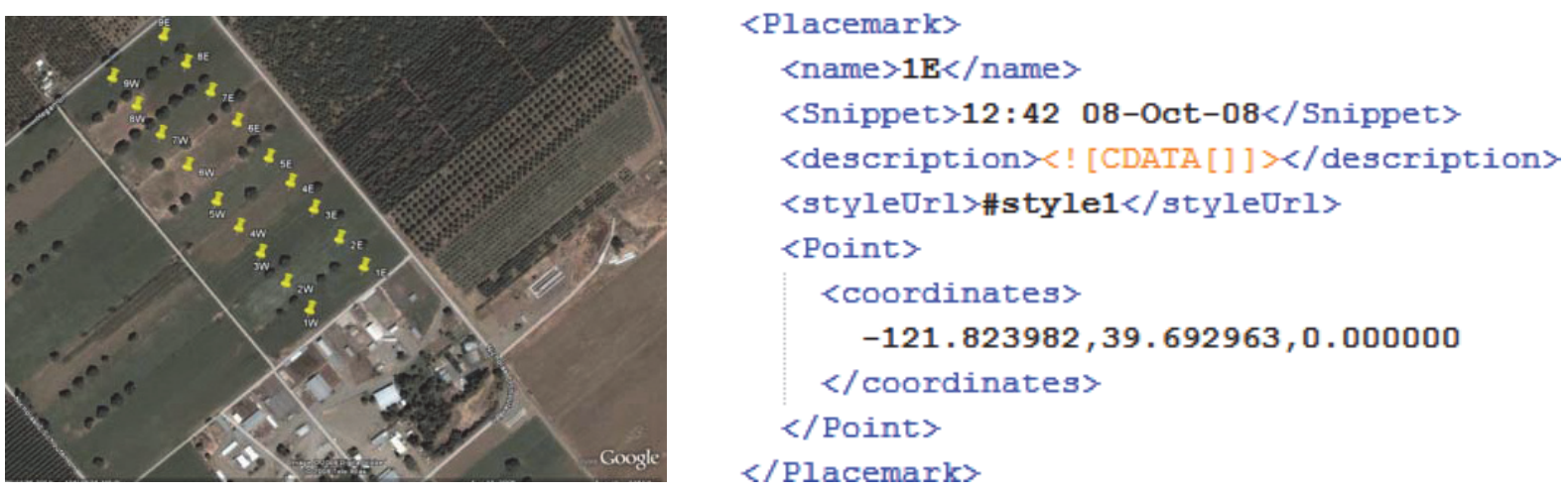

Figure 2. Locations of soil sampling points and the code of one placemark (Spiess, 2008a)

The element Multigeometry can be used as a container that makes possible to manage several geometry elements associated with the same feature as a single element. Let us consider, for example, a map describing the different soil types of a parcel. With the help of this element disjoint areas with the same soil types can be used as a single feature, although it consists of several polygons. A Multigeometry containing a Point geometry can have an icon and a custom description for its bubble and even StyleMap can be applied to map between two different styles. Agricultural districts are represented by MultiGeometry (Figure 3.) in the KML file that can be accessed from the Cornell University Geospatial Information Repository (http://cugir.mannlib.cornell.edu/datatheme.jsp?id=2). In this example the MultiGeometry element contains only Polygon elements, but the file stores also LineString elements to denote the boundary data. 

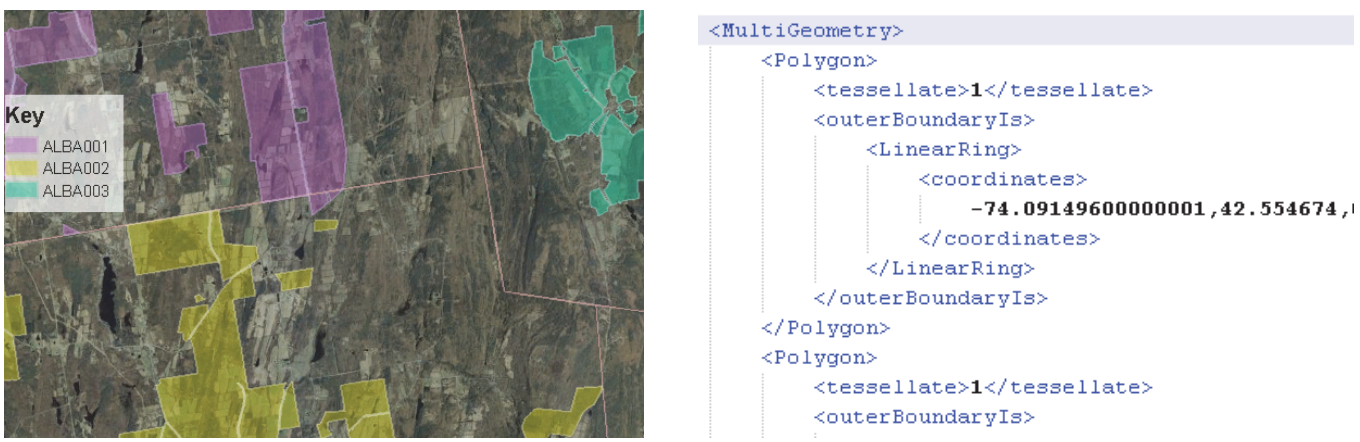

Figure 3. MultiGeometry and LineString elements displayed in Google Earth and its code fragment

The element Model is used to display a 3D object often stored and described in an external COLLADA file where the tag Link contains the reference of the file with extension dae. Models (e.g. buildings, bridges, mills, statues, monuments) can be also created by using applications such as Autodesk 3D Studio Max, Maya, Softimage XSI or Google SketchUp. The position, rotation and the measure of scaling can be set by further KML tags. New facilities or tools of a farm can be represented, for example, with a model as you can see an agricultural vehicle model on the website of Ultimate Holding Company (http://www.uhc.org.uk/portfolio.php?tag=5\&project=32).

The KML itself does not contain elements directly to create thematic maps although it is a very often used technique to display features based upon one or more of their attributes. One possible solution is to apply styles in this situation but some additional problems may have to be solved while representing the features with different sized or colored symbols (Sandvik, 2008). Thematic maps are great tools for visualizing of quantitative data (such as GDP on Figure 4., the amount of annual product, or the number of animals in a farm).

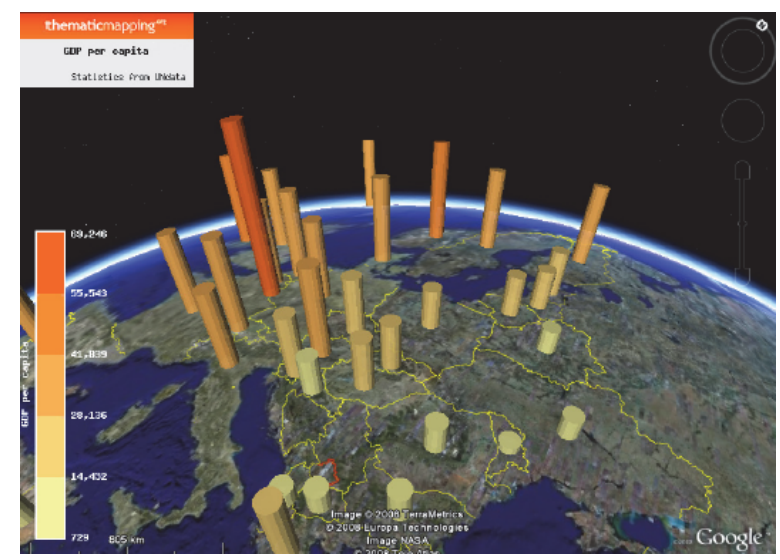

Figure 4. GDP per capital in Europeans countries in 2006 (Sandvik, 2008)

A $\mathrm{kml}$ file can be packaged up with a high rate since they are, basically, simple text files. The user interface of Google Earth provides a menu item (Save As) to create a $\mathrm{kmz}$ archive but it can be produced also manually using the program WinZip and renaming the archive with extension zip to $k m z$. This know-how reveals us how to look inside a kmz archive: after renaming a $k m z$ file to zip, it can be unpacked easily. Browsing the net, you will probably find mostly kmz files because of its following advantages:

- Less disk space is required for storing.

- Virtual earth browsers and the corresponding API-s can process it directly.

- No need to manage several files when working with a set of $\mathrm{kml}$ files.

If we want to produce $\mathrm{kmz}$ files all we need to remember is avoiding the usage of absolute references when defining paths to additional files. 


\section{Possible usages of $\mathbf{k m l}$ files}

Not only Google Earth and Maps support the kml files but several other applications such as NASA WorldWind, ESRI ArcGIS Explorer, Adobe PhotoShop, AutoCAD, Yahoo! Pipes. The item number of this list cannot be regarded as a constant one, because some works of amateur or professional developers appear from time to time on internet widening the range of possible applications. Scientists, researchers have used $\mathrm{kml}$ files to help explain and represent scientific phenomenon and to share scientific data and results.

The review of the application fields with some examples is grouped by the used softwares, but the desktop version of Google Earth is not discussed in detail because the kml files can be regarded as its native file format and the program itself is well-known even by the public. The Google Earth installed on a personal computer is said to be the browser of $\mathrm{kml}$ files.

\subsection{Online maps and globes}

The development of web technology and the appearance of the Web 2.0 technology have reshaped our need concerning publishing data. People want to see maps representing different locations also on the web, they want to reach web sites that help them to determine suggested directions to their destination, want to find any kind of geo-related information they are interested in (e.g. up-to-date data about the traffic conditions, new occurrences of avian flu, or foot-and-mouth-disease). The main aim of Web 2.0 technology is to provide a rich user experience, to encourage user participation and to offer API-s for users to be able to develop their own applications (Fu and Sun, 2011). The online map providers have reacted soon to the new demands and created and published their own open source Application Programming Interfaces (APIs) to ensure that any webpage could contain map sections as well. Some knowledge of programming is required of course, but also some JavaScript lines can transform our web page having a map section. Concerning the most popular virtual globe (Google Earth) there is a renewed hope that every sort of information on the state of the planet and its environment, from the levels of toxic chemicals to the incidence of disease, will become available to all with a few mouse clicks (Butler, 2006).

The knowledge of creating, managing and displaying $\mathrm{kml}$ files can be useful for the students majoring in agriculture as well. The field of precision agriculture is based mainly on the use of Global Positioning Systems (GPS), where the waypoints from the GPS unit can be downloaded and saved as a $\mathrm{kml}$ file establishing the visualization with Google Maps. Spiess (2008b), who works at the California State University, College of Agriculture, gives an overview how can this technique be taught for students.

MetBroker is also an interesting application that provides agricultural models with consistent and unified access to many different weather databases. Several plant growth models, disease and pest forecasting models utilizing MetBroker were developed and used as a framework for agricultural model development. Their map interfaces use Google Maps or Google Earth with kml files to select weather stations (Tanaka, 2006).

It is vital also for the agricultural companies and enterprises that their (would-be) clients could find them with ease using either the Google Search or the Google Maps. The free service of Google Places helps to make the business see on the web, but the position among the hits is very important because people usually visit only the first few hits. There are several ways to increase your business visibility in Google Maps search engines among which one is based upon well-structured $\mathrm{kml}$ files proving that SEO (Search Engine Optimization) can be realized also with the help of kml files (Beijk, 2009).

\subsection{Support of modeling}

In this field only our mind can be limited, the number of applications cannot. Enthusiastic amateurs make KML files, for example, to create the model of auto racetrack existed in the reality in order to use it in simulator programs (Pacsuta, 2011). The characteristic of the model has to be the same as that one in the reality to make it possible for the race car driver to practice as much as he can before the race. These experiences serve as an advantage when the real race is performed. 


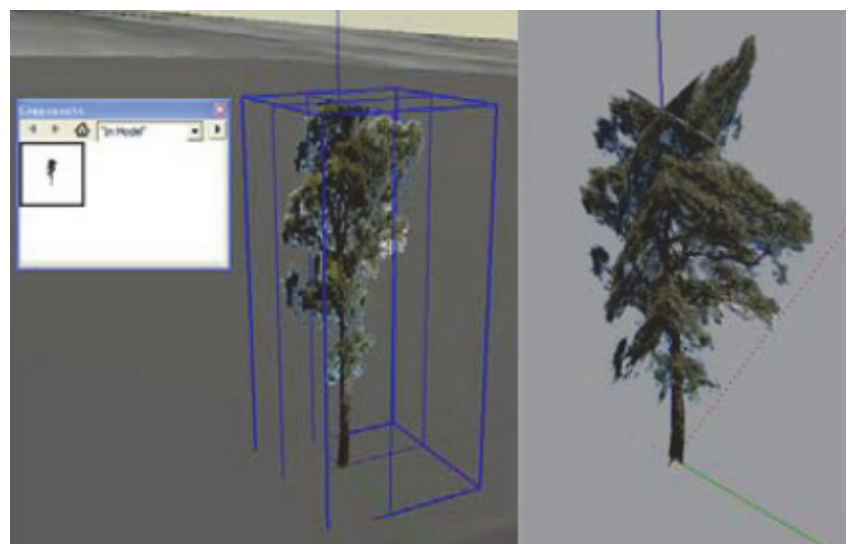

Figure 4. 3D tree modell created in Google Sketchup (Pettit et al, 2007)

Realistic representation of different surface objects (trees and other vegetation, power or water supply, built structures, fences) and subsurface information (soil profiles, water-table location) can serve the effective 3D visualisation in applications related to agriculture, that can help to many land managers having difficulty in understanding the full implications of their scenarios in map form. Pettit et al (2007) examined how they can move their application, eFarmer (http://www.landcarevic.net.au/resources/for-groups/mapping/efarmer) from 2D mapping to 3D form of visualization. They found that representing of 3D objects with Google SketchUp (e.g. revegetation, new plantations) can enhance their web based farm management software.

SketchUp supports basically the import of $\mathrm{kml} / \mathrm{kmz}$ files although the rate of supporting can vary examining different versions. The users require this feature that can be proved by the fact that a very interesting plugin was released some months ago again. This plugin has new innovative tools to import almost all the type of features from Google Earth to SketchUp. It can serve as a real bridge between these two popular programs.

\subsection{Import into geographical information systems}

One of the main functionality of the geographical information systems is to visualize georelated objects based upon their geometry stored and determined by coordinates in a reference system. Spatial analysis, the study of geo-related features, and the relationships between them can be applied to many areas of the agriculture industry. Regardless of scale -whether at the farm field level analyzing crop yield information or across an entire country- GIS is becoming fully integrated and widely accepted for assisting government agencies to manage programs that support farmers and protect the environment. These are the agriculture GIS application in the field (Kumar, 2011).

- Combining agronomic and economic data sets

- Field data interpolation

- Decision support for farm management

- Farm asset allocation

- Field input reporting

- Regulatory compliance

- Subsidy claims

Each GIS has its own native file format, but they provide also tools for reading or importing another type of files. This statement is valid in the case of kml files too, for example the AutoCAD Map can import a kml file as well as the ArcGIS from ESRI. 


\section{Methods for sharing $\mathrm{kml}$ files}

Everything that happens in our world, happens somewhere and nowadays people want to know and see or even to show the answer for their question of where also visually. Nowadays not only professionals but also ordinary people decide to publish custom geo-related data. The methods can be divided into two groups taking into account the presence of visualization.

The simplest method is to create the $\mathrm{kml}$ files, share them as files and let the end users download them and bother with the visualization. In this case we suppose that a suitable desktop application (e.g. Google Earth) is installed on the computer of the enduser. Several web pages can be found on internet applying this techniques; one of them (http://www.geology.sdsu.edu/kmlgeology/) belongs to the San Diego State University and hosts a collection of geoscience related examples from geology. Food and Agriculture Organization of the United Nations (FAO) runs also a portal called GeoNetwork (http://www.fao.org/geonetwork/srv/en/main.home), where several KML files can be accessed to support decision making and enhance understanding of the benefits of geographic information used in agriculture. In FAO Core Datasets contains geospatial information about farming (e.g. biodiversity hotspots in areas poorly suited to rainfed agriculture) and livestock (e.g. Global Poultry Density).

To share the files, not only web pages containing URL-s, but e-mail sending systems can be used perfectly due to the property of being text files.

Sometimes the aim is not only to share the pure $\mathrm{kml}$ file, but its geovisualized content, so some web mapping service applications are needed to visualize our custom data on internet. The Google Maps, Bing Maps, Yahoo! Maps, MapQuest can help to achieve this goal, and what is more they are free for non-commercial use and can be embedded into web pages via APIs. All of them have its own application programming interface (API) meeting the requirements of the public and the professionals as well. Although these APIs are different we can handle them uniformly with the help of Mapstraction (http://mapstraction.com). Basically, Mapstraction is a library that provides a common API for various Javascript mapping APIs to enable switching from one to another with ease, so developers have to write the codes just once not taking care of the different APIs of map providers. This open-source library supports $\mathrm{kml}$ elements, but not all of them just like the other, above mentioned APIs.

\section{Preparing methods}

The user interface of Google Earth has tools for creating certain types of elements easily with some mouse clicks, but creating of some types of objects are not supported at all. For example, Multigeometry, Network links or Screen overlays are all frequently-used elements although you have to use a simple text editor to enter $\mathrm{kml}$ codes from scratch or to edit an existing file. Nevertheless, it is a good strategy to produce the first version of the $\mathrm{kml}$ file with the user interface (it is very convenient to set the elements LookAt, Camera, etc. in an interactive environment) and then only to edit and complete the pre-prepared file. The editing includes removing the redundant style definitions and ensures the opportunity for applying shared styles too.

GIS software products are usually able to export (some) data of their native file format to $\mathrm{kml}$. Besides, the most popular internet search engine lists more than 24 millions hits if you type the "export to kml" words so you can find converter programs, web-pages for many file formats such as $d x f, t a b, s d f, x l s, c s v, g p x$, etc. There are also some open source applications (Regionator, GeoServer, GDAL tools) that support producing kml files allowing flexibility in the terms of use. Their main drawback is that the learning curve can sometimes high. (Ballagh et al., 2011).

People with affinity for programming can write themselves small applications that can produce $\mathrm{kml}$ files based upon any kind of database containing georeferenced data. Remember, that a $\mathrm{kml}$ file is a simple text file which makes it easy to create, although it has to follow strict rules. The Hungarian Digital Toponym Registry (http://mnytud.arts.unideb.hu/mdh), for example, stores the data in a 4D 
database, but the geovisualization is based upon $\mathrm{kml}$ files generated by custom $4 \mathrm{D}$ methods developed by programmers (Zichar and Tóth, 2011).

\section{Experiences}

Different APIs do not support necessarily all the KML elements, so a list of the non-supported elements is published in the home pages of the APIs, but sometimes it contains not enough amount of details. Let us consider the element Region that is supported by the Google Maps API V3 according to its website, but unfortunately the lack of implementing its Lod children element destroys its effective usage. The developments do not stop, of course, so we have to track changes regularly to be able to keep our websites updated.

Not only 2D online maps but virtual globes, such as Google Earth, can also be embedded into web pages. Nevertheless, there are main differences between the applied technologies and the visualization. Table 1. summarizes my own experiences when I tried to embed the two most popular applications of Google into a webpage. After reviewing the table we can say that working with GE requires much efforts but it ensures higher level of functionality.

Table 1. Compairing the charactristic of embedded Google Maps and Google Earth

\begin{tabular}{|l|l|l|}
\hline & Google Maps (embedded) & Google Earth (embedded) \\
\hline Representation & $2 \mathrm{D}$ & 2D, 3D \\
\hline Need of API key & No need of API key for V3. & API key is needed. \\
\hline Level of supporting KML elements & Limited. & High. \\
\hline Number of methods for using kml & One. & Three. \\
\hline $\begin{array}{l}\text { Default appearance of a kml } \\
\text { placemark }\end{array}$ & Icon. & Icon with label. \\
\hline Event handling & Supported. & Supported. \\
\hline
\end{tabular}

Sometimes a trick can solve or ease some problems met while trying to comply the wishes of the user. The embedded Google Earth, for example, insists on displaying the icon of a placemark, unless we omit the usage of placemark bubbles. Nevertheless, if the vision of the icons is disturbing then defining a shared style with a very small icon size (in case of the standard icons: 0.2 ) can almost hide the pictures of the icons while the user is still able to click on it to make the bubble appear with custom information.

Finally, arguments for and against using $\mathrm{kml}$ files are reviewed. The following properties can be considered as advantages:

- Easy to read and to share.

- Small size with high rate of zipping.

- Standard version (2.2).

- Effective visualization either in desktop or on the web.

- Several ways of preparation.

Some drawbacks highlighting when it is not recommended to base the geovisualization on kml files:

- Not supporting much attribute data.

- No tools for performing data analysis.

- Continuous need of internet connection. 


\section{Conclusion}

The geographical location of the objects, events often plays an important role in agriculture, implying the usage of geographic information systems to handle the geo-related and the attribute data together. The Keyhole Markup Language provides a set of features for displaying data in a very effective way stressing the visualization. The possible applications of $\mathrm{kml}$ files are diverse and do not concentrate only to the maps and virtual globes any more. The online map and virtual globes providers developed and are developing continuously their own APIs that makes it possible to meet the requirements of the Web 2.0 technology but the rate of supporting KML elements is different according to the APIs. The discussed examples show that kml files are often used in agricultural applications as well and demonstrate its power in geovisualization.

\section{References}

Ballagh, L. M., Raup, B. H., Duerr, R. E., Khalsa, S. J. S., Helm, C., Fowler, D., Gupte, A. 2011. Representing scientific data sets in KML: Methods and challenges. Computers \& Geosciences 37, 57-64.

Beijk, M. 2009. KML and sitemaps for SEO - The definite guide. (http://www.martijnbeijk.com/tutorial/usingkml-for-local-seo/). Last download 25.09.2011.

Butler, D., 2006. Virtual Globes: the web-wide world. Nature 439, 776-778.

Fu, P., Sun, J. 2011. Web GIS. Principles and Applications. Redlands, California. ESRI Press.

Kumar, R., 2011. GIS based agriculture, (http://agropedia.iitk.ac.in/?q=node/2297/revisions/14728/view) Last download 15.11.2011.

Pacsuta, T. 2011. Versenypálya modellezése KML alapokon. Diplomamunka. Debreceni Egyetem.

Pettit,C. J., Bishop, I.D., Cartwright, W.E., Park, G., Kemp, O., 2007. Enhancing Web Based Farm Management Software Through The Use of Visualisation Technologies, In Oxley, L. and Kulasiri, D. (eds) MODSIM 2007 International Congress on Modeling and Simulation. Modeling and Simulation Society of Australia and New Zealand, December 2007, 1280-1286.

Sandvik, B. 2008. Using KML for Thematic Mapping. Research Paper. Edinburgh. University of Edinburgh.

Spiess, M. 2008a. Dairy Pasture Soil Sample Points.

(http://maps.google.com/maps/ms?hl=en\&ie=UTF8\&msa=0\&msid=109599488892121516282.000458c33690c3 0c4c3e2\&t=h\&z=16) Last download 31.10.2011.

Spiess, M. 2008b. Simple Tools for Using GPS in Your Course. (http://www.agedweb.org/GPS/GISGPS\%20Tools.pdf) Last download 31.10.2011.

Tanaka, K. 2006. The Utility Web Applications for MetBroker, In Proc. AFITA2006 5th Conference of Asian Federation for Information Technology in Agriculture, Bangalore, India, Macmillan Publishers India. 603-609.

Wernecke, J. 2009. The KML Handbook. Boston. Addison-Wesley.

Wilson, T.(Ed.) 2008. OGCKML.OGC07-147r2. OpenGeospatialConsortium, Inc., 251 pp (http://portal.opengeospatial.org/files/?artifact_id=27810) Last download 31.10.2011.

Zichar, M., Tóth, V. 2011. Informatika a nyelvtudomány szolgálatában. In Proc. Informatika a felsőoktatásban 2011 konferencia, 843-848. Cser, L., Herdon, M. Debrecen. Debreceni Egyetem. 